\title{
Aspects of acute care in Sleep Medicine
}

\author{
Roop Kaw $\cdot$ Babak Mokhlesi
}

Received: 21 August 2012 /Accepted: 17 September 2012 /Published online: 27 September 2012

(C) Springer-Verlag Berlin Heidelberg 2012

Epidemiologic studies have repeatedly shown an association between obstructive sleep apnea (OSA) and cardiovascular endpoints including myocardial infarction, arrhythmias, congestive heart failure, stroke, and sudden cardiac death, even after adjustment for known cardiovascular risk factors. Gami et al. reviewed 112 reports of sudden death and found that almost half of the patients with polysomnographically confirmed OSA died during sleep hours (12 midnight to $6.00 \mathrm{am}$ ) compared to $21 \%$ of those without OSA (RR 2.57) [1]. Of further interest was the fact that the risk of sudden death was related to disease severity of OSA. Anecdotal reports and case series of sudden cardiac arrhythmias and sudden cardiac death associated with severe OSA and hypoxemia have been reported during overnight polysomnographic recordings in the sleep labs [2]. The slow advent of inpatient polysomnography has lent more support to such claims. Recently, recurrent episodes of "cardiopulmonary arrest" were reported in a hospitalized patient with undiagnosed severe OSA during the night of the sleep study. Respiratory arrest and cerebral hypoxia during REM sleep were documented on polysomnography and no subsequent near arrest events were noted and possibly mitigated with the use of continuous positive airway pressure (CPAP) [3]. Another study looking at the prevalence of OSA in the medical intensive care unit reported 30- to 90-s apneic periods followed by a prolonged period of flat/absent EEG activity among two patients one of whom arrested

\section{R. Kaw $(\square)$}

Departments of Hospital Medicine and Outcomes Research, Anesthesiology, Cleveland Clinic,

9500 Euclid Avenue, Suite A-13,

Cleveland, OH, USA

e-mail: kawr@ccf.org

\section{B. Mokhlesi}

Sleep Disorders Center and Sleep Fellowship Program, Section of Pulmonary and Critical Care, University of Chicago, 5841 S. Maryland Avenue, MC6076/Room M630,

Chicago, IL 60637, USA and died [4]. Whether OSA is an independent risk factor for sudden cardiac death requires further research, but high-resolution pulse oximetry or inpatient polysomnographic monitoring of acutely ill patients may help provide a clue.

Sudden cardiac death (or near death) has been attributed to "depressed or failed arousal" followed by life-threatening hypoxemia in patients with severe OSA. In fact, this may be true among some obese patients who may average 50 or more severe cyclic desturations per average hour of sleep every night and may be at particular risk for acquired arousal failure [5]. Others have attributed the depressed arousal mechanism to sleep deprivation and fragmentation among hospitalized patients [6]. Narcotics, especially patient-controlled analgesia, spinal anesthesia, and sedatives can further increase or delay the arousal threshold and thereby compromise airway patency and survival among such patients. Undoubtedly, further studies are needed to understand the mechanisms of apnea termination and arousal response particularly among acutely ill hospitalized patients, postoperative patients, and patients receiving sedatives and narcotics.

In the operating room, difficult intubation has been reported to occur eight times as often among OSA patients compared to controls [7]. Unanticipated transfers to ICU after surgery are more common among OSA patients as is the length of hospital and ICU stay $[8,9]$. Up until recently, increased incidence of postoperative respiratory failure was not consistently reported among patients with OSA undergoing elective noncardiac surgery, mainly due to reasons of the study sample size, the definition of "respiratory failure" used for study purposes, as well as the study design (e.g., if the study was a quality improvement study). Recently, however, a large study of approximately 50,000 patients with OSA undergoing general and orthopedic surgery reported a fivefold increase in intubation and mechanical ventilation after surgery [10]. A recent meta-analysis of studies 
of OSA patients undergoing elective noncardiac surgery reports a higher incidence of postoperative acute respiratory failure (odds ratio $(\mathrm{OR}) 2.43$, confidence interval (CI) $1.34-4.39, p=0.003)$ and postoperative cardiac events $(\mathrm{OR}=2.07$, CI $1.23-3.50, p=0.007)$ [11]. Early reports also show that the incidence of postoperative respiratory failure may be particularly high among patients with obesity hypoventilation syndrome which is more often unrecognized before elective noncardiac surgery.

There is a growing body of literature examining the role of diagnostic testing for sleep-disordered breathing during an acute hospitalization. Specifically, there is an interest in exploring the role of diagnosis (either by limited cardiopulmonary testing or by full-montage polysomnography) and treatment with CPAP on patient outcomes. Studies have examined the role of early diagnosis and treatment of sleep-disordered breathing in the postoperative period, during an admission due to decompensated heart failure, acute ischemic stroke, or acute coronary syndromes. Observational studies suggest that treatment of OSA in patients undergoing percutaneous coronary interventions leads to decreased cardiac death [12]. Evidence shows that CPAP treatment in OSA alters electrophysiologic parameters (viz., rate dependence of QT and RT intervals) which are known markers of predisposition to ventricular tachycardia in postmyocardial infarction patients [13]. Boussignac CPAP has been shown to improve the $\mathrm{PaO} 2 / \mathrm{FiO} 2$ ratio at 1 and $2 \mathrm{~h}$ postextubation [14] as well as improved lung function at $24 \mathrm{~h}$ among patients after bariatric surgery. Recent evidence from a randomized controlled trial also shows that among patients with acute ischemic stroke, the use of auto-CPAP initiated during the hospitalization was associated with an improvement in the NIH stroke scale $(-3.0$ to $-1.0, p=0.03)$ compared to those not provided with an auto-CPAP for a $30-$ day period [15]. Another similar study among patients admitted with acute decompensated heart failure, diagnosed to have OSA in the hospital, and randomized to receive autoCPAP while hospitalized for heart failure exacerbation showed significant improvements in left ventricular ejection fraction, cardiac filling pressures, and weight loss in the treatment group [16].

The findings of these early studies will require confirmation in larger trials. All the listed evidence should serve as a catalyst for our focus on how sleep-disordered breathing can impact our clinical practice in the acute care setting, intensive care, and postoperative care arenas.

\section{References}

1. Gami AS, Howard DE, Olson EJ, Somers VK (2005) Day-night pattern of sudden death in obstructive sleep apnea. N Engl J Med 352(21):1206-1214

2. Chokroverty S, Sahota P (2011) Acute and emergent events in sleep disorders. Oxford University Press, New York

3. Khoo SM, Mukherjee JJ, Phua J, Shi DX (2009) Obstructive sleep apnea presenting as recurrent cardiopulmonary arrest. Sleep Breath 13:89-92

4. Dyken ME, Yamada T, Glenn CL, Berger HA (2004) Obstructive sleep apnea associated with cerebral hypoxemia and death. Neurology 62(3):491-493

5. Peppard PE, Ward NR, Morrell MJ (2009) The impact of obesity on oxygen desaturation during sleep-disordered breathing. Am J Resp Crit Care Med 180(8):788-793

6. Guillenminault C, Rosekind M (1981) The arousal threshold: sleep deprivation, sleep fragmentation obstructive sleep apnea syndrome. Bull Eur Physiopathol Respir 17:341-349

7. Siyam MA, Benhamou D (2002) Difficult endotracheal intubation in patients with sleep apnea syndrome. Anesth Analg 95:1098-1102

8. Gupta RM, Parvizi J, Hanssen AD, Gay PC (2001) Postoperative complications in patients with obstructive sleep apnea syndrome undergoing hip or knee replacement: a case-control study. Mayo Clin Proc 76(9):897-905

9. Kaw R, Pasupuleti V,Walker E, Ramaswamy A,Foldvary-Schafer $\mathrm{N}(2012)$. Postoperative complications in patients with obstructive sleep apnea. Chest 141(2): 436-41

10. Memtsoudis S, Liu SS, Ma Y, Chiu YL, Walz JM, Gaber-Baylis LK, Mazumdar M (2011) Perioperative pulmonary outcomes in patients with sleep apnea after noncardiac surgery. Anesth Anlag 112(1):113-121

11. Kaw R, Chung F, Pasupuleti V, Mehta J, Gay PC, Hernandez AV( 2012) Meta-analysis of the association between obstructive sleep apnea and postoperative outcomes. British Journal of Anesthesia. doi:10.1093/bja/aes308

12. Cassar A, Morgenthaler TI, Lennon RJ, Rihal CS, Lerman A (2007) Treatment of obstructive sleep apnea is associated with decreased cardiac death after percutaneous coronary intervention. J Am Coll Cardiol 50(14):1310-1314

13. Roche F, Barthelemy JC, Garet M, Duverney D, Pichot V, Sforza E (2005) Continuous positive airway pressure treatment improves the QT rate dependence adaptation of obstructive sleep apnea patients. Pacing Clin Electrophysiol 28(8):819-825

14. Wong DT, Adly E, Thapar S, Maxted GR, Chung FF (2011) A comparison between the Boussignac continuous positive airway pressure mask and the venturi mask in terms of improvement in the $\mathrm{PaO} 2 / \mathrm{FiO} 2$ ratio in $\mathrm{m}$ orbidly obese patients undergoing bariatric surgery: a randomized controlled trial. Can J Anaesth 58(6):532-539

15. Bravata DM, Concato J, Fried T, Ranjbar N, Sadarangani T, McClain V, Struve F, Zygmunt L, Knight HJ, Lo A, Richerson GB, Gorman M, Williams LS, Brass LM, Agostini J, Mohsenin V, Roux F, Yaggi HK (2011) Continuous positive airway pressure: evaluation of a novel therapy for patients with acute ischemic stroke. Sleep 34(9):1271-7

16. Khayat RN, Abraham WT, Patt B, Pu M, Jarjoura D (2009) Inhospital treatment of obstructive sleep apnea during decompensation of heart failure. Chest 136(4):991-997 